Dilute acid first showed a blue scale, changing to orange. The ncedle point, howcver, remained gray.

Distilled water showed very little rust. Carbondioxide water, however, showed more. $\mathrm{NaOH}$ and $\mathrm{KOF}$ (10\% solutions) showed little effect.

Mr. Easton showed some needles which had touched the concentratcd acid, the necdlc end separated into fibres like a brush.

To determine the oxygen in air, Dr. Allen filled a test tube about onethird full of pyro, marked the level with a rubber band, filled to mark with $\mathrm{KOH}$ solution, closing with thumb, shaking and inverting into water. When cool, close reverse and from burette measure residual air space; also by burette determine volume of air taken.

Mr. Allen also showed an apparatus in which the measured air in an eudiometer was passed into a cylinder containing copper gauze, wet with alkaline anmonitum chioride. After absorption the air was forced back by leveling bottles into the eudiometer and remeasured.

Dr. Woodhull used a 25 c.c. cudiometer, in a cylinder abott the same length, filled with water. The air in the endiometer is measured at adjusted levels and the eudiometer lowered over a wirc holding a phosphorus pellet. After absorption, the andiometer is raised, to remove the $P$ and adjust levels, and re-read.

Dr. Fay showed a picce of apparatus combining in onc straight tube the eudiometer and absorption chamber. The lower (closed end) half of a tube contained phosphorus rods, $1 / 8$ inch in diameter, held in place by a perforated stopper.

The upper half was graduated from the end. The tube having been filled with water, is partly emptied and the air space observed. It is then closed and inverted, over water, whereby the air passed into the phosphorts chamber; after cooling it is closed and again inverted, and the residual air measured. After filling with water, it is again ready for use. Dr. Fay used a vessel constructed like an "unspillable" ink well. The tube was closed by being pressed against the bottom of the vesscl, and inverted, when the vessel furnished water to replace the absorbed oxygen. Dr. von Nardroff and Mr. Huntington used the same kind of tube, but inverted into a vessel of water, Dr. von Nardroff opening and closing the tube by a brass plate held by a spring; $\mathrm{Mr}$. Huntington by a cork stopper with a lateral perforation, to allow its opening or closing without affecting the pressure.

M. D. Sorron.

\title{
THE COLLEGE ENTRANCE EXAMINATION BOARD'S SYLLABUS IN CHEMISTRY.
}

M. D. SoHon.*

Morris High School, New York.

The syllabus in chemistry for the New York High Schools was recommended to the City Superintendent by a committee of seven teachers appointed from the various 'schools in June, 1901.

As one of the requirements for graduation then announced, the pupil

* Mr. Solon was chairman of the committee referred to in the paper.--Fid 


\section{$298 \quad$ 2 cbool जcience ano Matbematics}

should pass the tests of the Collegc Entrance Examination Board. In view of this fact the committee recommended the adoption of the Board's syllabus:

The syllabus represented a new course of work, differing in content and method from usual courses and outlined a systematic development of the stbject radically different from standard tests. It has received criticism on various points, much that has been said I think unfair, if we look to the intent of the syllabus. In the following I have attempted to point out what I consider the purpose of the course of work, and I refrain from criticising it.

The opening paragraphs are clearly a list of suggested topics. The critcised list of cxperiments is not merely a list of exercises that are to be considered acceptable, but each experiment is carefully stated not alone as to its material, but the sequence points to a definite form of instruction, of high standard with carefully selected material-inductive instruction, with individual quantitative work.

In the following outline I have mentioned each expcriment in its order in the syllabus (experiment numbers are given):

In the introductory section, (1) the composition of the air is determined; (2) by the action of heat on a certain body, a metal is obtained and a material acting similar to something in the air. (3) Starting with a metal the same (physical) process brings about a reverse action. (4) Such (metallic) oxides have certain general resemblances and differences. Similarly non-metallic substances are used (5-6).

This section furnishes clear cut illustrations of chemical action, solubility, distinctions as to acid, base, salt and neutralization.

Physical conditions, tomperature and pressure, as the factors in the states of matter. $(8,9,10$.

The chemistry of common things is begun in a thorough study of the chemistry of water.

(11) Oxygen (reviewing No. 1, No. 6) is prepared and (12) studied, as to its chcmical and physical properties. This introdtuces (13) water, which is decomposed by sodium; (14) hydrogen is also prepared in the usual way that its characteristics may be noted (15).

The relations by weight and by volume, in which $\mathrm{H}$ and $\mathrm{O}$ combine, are to be detcrmined, $(16,17)$, and having produced a quantity of the material, it is shown, in its physical properities, to be identical with water (18).

Water is then electrolysed (19) and the products shown to be qualitatively and quantitatively identical with the materials used in the former synthesis.

The vapor density of water (20) is determined and the formula derived.

These experiments lead in a masterly manner to the qualitative and quantitative proof of the composition of water by analysis and synthesis, and to its symbol. The work is necessarily long and intricate, so difficult 
that few texts attempt to develop the general notion expressed in a chemical formula, but it is here brought out in a series of concise exercises.

Preliminary to the further study of compounds, are a number of exercises for the detection of metals-not a systematic course in qualitative analysis, but such tests as would indicate whether or not, $e$. g., blue vitriol is a copper compound.

Any of the metals naned could be detected by at least one of the four simple tests: the flame tests (21); borax beads (22); cobalt nitrate coloration (23); reduction by zinc $(24,25)$.

Chlorine is prepared (26) and studied (27) as was oxygen; combined with hydrogen (28) the acid examined and analysed $(29,30)$ affording an excellent illustration to introducc Avogadro's Law. Other compounds of chlorine are prepared and studied by the methods 21,25 .

Similarly the other halogens are prepared and studied in their typical compotnds, and relative "chemism" $(32,37)$.

The relative activitics and weights being noted, the next topic is the determination of combining and atomic weights $(38,39,40)$.

The same course of treatment is indicated for the study of sulphur, its acids and salts $(41,46)$ and for nitrogen oxides and acids.

Valence and oxidation and reduction are introduced with the change from chromatc to di-chromate and vice versa (52), chromium as acid and base forming element (53), and the iron salts $(54,55)$.

The same general treatment is extended to carbon. Carbon is identified (56) in its compounds, some of these being prepared (57, $58)$; carbon dioxide is studied in some of its important relations $(59,61)$.

Alcohol, ether and soap are also suggested $(62,64)$.

In the foregoing, each experiment in the "list" has been included, and its object shown (as it appears to me.) I do not believe that $I$ have introduced any topic not called for by the syllabus. But it should be noted that I have mentioned but a small proportion of the topics included in the "outline," the metals have been only incidentally touched, and the ustal technical treatment ignored.

\section{REPORT OF THE MATHEMATICS SECTION NEW YORK STATE TEACHERS' ASSOCIATION. \\ W. H. MetzLer, Syracuse Univorsity, Chairman.}

Prof. Metzler presentcd a paper on "Geometry," the main object of which was to consider the following questions:-What is geometry? Why should it be studied? How should it be taught? A somewhat detailed account, also was given of the results that should be derived from the study, and finally, some general conclusions were reached as to methods of teaching. 